\title{
ON CORRELATIONS BETWEEN EXTENDED DEFECTS FORMATION AND ELECTRON CONCENTRATION CHANGES CAUSED BY ANNEALING OF GaAs:Te
}

\author{
J. BoRYSIUK, J.A. KozUBowsKI
}

Faculty of Material Science and Engineering, Warsaw University of Technology Narbutta 85, 02-524 Warsaw, Poland

AND T. SŁUPIŃSKI

Inst. of Experimental Physics, Warsaw University, Hoża 69, 00-681 Warsaw, Poland

Extended type defects in heavily doped GaAs:Te $\left(n \approx 1 \times 10^{19} \mathrm{~cm}^{-3}\right)$ after annealing at $700^{\circ} \mathrm{C}$ and $1150^{\circ} \mathrm{C}$ were studied by transmission electron microscopy, by high resolution technique and energy-dispersive X-ray analysis. Assuming, according to the literature that these defects are enriched in impurity atoms it is suggested that this solely is not sufficient to explain changes of electrical properties during annealing. Estimated amount of atoms involved in faulted dislocation loops seems to be too small, energy-dispersive $\mathrm{X}$-ray microanalysis of precipitates did not show large differences in composition with the matrix.

PACS numbers: $61.72 . \mathrm{Nn}, 61.72 . \mathrm{Vv}, 72.80 . \mathrm{Ey}$

\section{Introduction}

In $n$-type GaAs crystals heavily doped with Te [1], Si [2], Se [3] and S [4] extended type defects are observed after growth or heat tretment. It is also known [5] that similar heat treatment produces large changes of free electron concentration in these materials. Here we are interested in quantitative relation between changes of free electron concentration caused by annealing and the amount of impurity atoms involved in large defects. We try to verify a hypothesis that the electrical changes are mainly due to extended defects formation.

Structural defects reported in $n$-GaAs are stacking faults, dislocation loops and precipitates, their density and size depend on annealing temperature. Prismatic dislocation loops on $\{110\}$ planes and faulted loops on $\{111\}$ planes were interpreted as vacancy type loops [6] or as interstitial type loops [1]. It was suggested [1] that faulted loops on $\{111\}$ planes contain platelet shape Ga-Te precipitates resulting from decomposition of supersaturated solid solution. It was also 
proposed [6] that precipitate particles attached to the cores of dislocation loops are Te-rich phase. Recently it was observed [2] that similar dislocation loops in GaAs:Si contain an atomic layer enriched in Si. We estimate concentration of defects resulted from annealing and give chemical microanalysis of precipitates.

\section{Experimental procedure}

The samples studied were cut from a single crystal of GaAs doped with about $1 \times 10^{19} \mathrm{~cm}^{-3} \mathrm{Te}$, grown by Czochralskitechnique. Two types of annealing conditions were applied, $T=1150^{\circ} \mathrm{C}$ during 2 hours and $T=700^{\circ} \mathrm{C}$ during $74 \mathrm{~h}$ or $361 \mathrm{~h}$, with fast cooling in water (rate about $100^{\circ} \mathrm{C} / \mathrm{s}$ ). Before and after each annealing the electron concentration were determined by IIall and resistivity measurements in Van der Pauw [7] configuration at roon temperature. Thin foils for transmission electron microscope (TEM) observations were prepared from (100) or (110) oriented samples by chemical thinning in $\mathrm{H}_{2} \mathrm{SO}_{4}-\mathrm{H}_{2} \mathrm{O}_{2}-\mathrm{II}_{2} \mathrm{O}$ 5:1:1 solution. The foils were examined in PHILIPS EM 300 electron microscope operated at $100 \mathrm{kV}$ and JEOL JEM 3010 microscope operated at $300 \mathrm{kV}$ used also for high resolution images and energy-dispersive X-ray analysis (EDXA). For EDXA an electron beam was focused to a diameter of $20 \mathrm{~nm}$ and positioned to a defect or surrounding matrix. The nature of stacking fault on $\{111\}$ plane was determined by Gevers et al. method [8] and the direction of Burgers vectors of dislocations by using the condition of disappearing of contrast at $g \cdot b=0$ ( $g$ is the diffraction vector) by Hirsh et al method [9].

\section{Results and discussion}

An example of microstructure images observed in GaAs:Te after annealing at $T=700^{\circ} \mathrm{C}$ is presented in Fig. 1 . Two kinds of prismatic dislocation loops are visible, one of them parallel to $\{110\}$ planes with Burgers vector $b=(1 / 2) a\langle 110\rangle$ and the other parallel to $\{111\}$ with $b=(1 / 3) a\langle 111)$ containing the stacking fault of extrinsic type. In Fig. 1 the precipitates are also seen, lying on dislocation loops or in the matrix. After annealing at $T=1150^{\circ} \mathrm{C}$ very small density of dislocation loops and precipitates were observed.

The quantitative results of observation are collected in Table. Density of defects was calculated for several regions of sample and averaged values are given. Assuming, according to [1] that $\{111\}$ loops contain a single layer of tellurium we could roughly estimate the amount of $\mathrm{Te}$ atoms present in loops. The value obtained, $2 \div 6 \times 10^{18} \mathrm{~cm}^{-3}$ (Table, column 6 ), is about twice smaller than the change of free electron concentration. Thus we suggest that the creation of dislocation loops with $\mathrm{Ga}-\mathrm{Te}$ layer need not be the only reason of reduction of tellurium donor atoms and electron concentration during annealing.

Another type of defects which could contain an impurity [6] are precipitates on dislocation loops, visible in Fig 1 and in high resolution mode in Fig. 2. The precipitates are coherent with the matrix, these defects are not voids. Their diameter is large enough (about $20 \mathrm{~nm}$ ) for chemical microanalysis to be attempted. Results are presented in Fig. 3 for an electron bean focused in the precipitate region (Fig. 3a) or in surrounding matrix (Fig. 3a). The inserts show that EDX intensity due to Te taken at precipitate region is not more than twice higher 

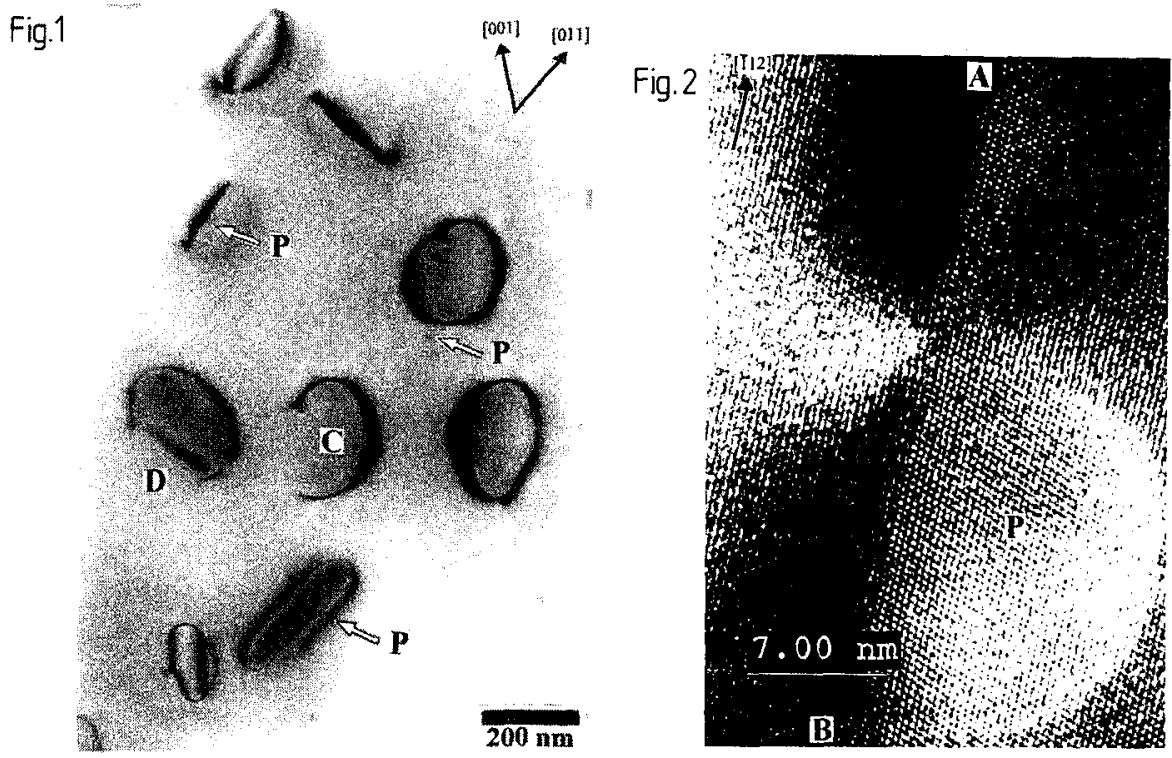

Fig. 1. Bright-field electron micrograph of dislocation loops in Te-doped GaAs annealed at $T=700^{\circ} \mathrm{C}$ for 361 hours, sample orientation (100). $C$ - perfect dislocation loop on the (110) plane; $D$ - partial dislocation loop containing the stacking fault on the (111) plane; $P$ - precipitate.

Fig. 2. High-resolution electron micrograph of Te-doped GaAs taken at $300 \mathrm{kV}$ from (110) oriented sample. Micrograph shows the precipitate $(P)$ attached to the partial dislocation loop containing the stacking fault $(A-B)$.
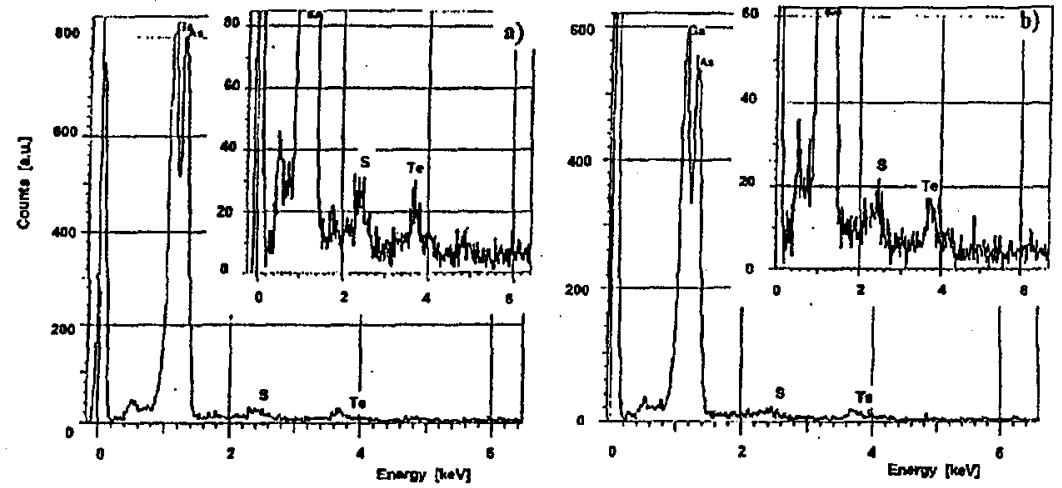

Fig. 3. EDX spectra from Te-doped GaAs: (a) from the precipitate attached to the partial dislocation loop; (b) from the matrix. Notice - the presence of sulphur is caused by chemical thinning of the sample for TEM observations.

than that in the matrix. Supposing that the precipitate is only a part of volume from which EDX signal is taken (not less than about 1/5) and that that the 
The quantitative results of the observations for Te-doped GaAs.

TABLE

\begin{tabular}{c|c|c|c|c|c}
\hline \hline $\begin{array}{c}\text { Annealing } \\
\text { temperature } \\
{\left[{ }^{\circ} \mathrm{C}\right]}\end{array}$ & $\begin{array}{c}\text { Annealing } \\
\text { time } \\
{[\mathrm{h}]}\end{array}$ & $\begin{array}{c}\text { Free electron } \\
\text { concentration } \\
{\left[\mathrm{cm}^{-3}\right]}\end{array}$ & $\begin{array}{c}\text { Dislocation loops } \\
\text { density } \\
{\left[\mathrm{cm}^{-3}\right]}\end{array}$ & $\begin{array}{c}\text { Precipitates } \\
\text { density } \\
{\left[\mathrm{cm}^{-3}\right]}\end{array}$ & $\begin{array}{c}\text { Te atoms in } \\
\text { loops concentr.* } \\
{\left[\mathrm{cm}^{-3}\right]}\end{array}$ \\
\hline 1150 & 2 & $1.4 \times 10^{19}$ & - & - & - \\
\hline \multirow{2}{*}{700} & 74 & $4 \times 10^{18}$ & $2 \div 5 \times 10^{13}$ & $3 \div 9 \times 10^{13}$ & $2 \div 6 \times 10^{18}$ \\
\cline { 2 - 6 } & 361 & $2.5 \times 10^{18}$ & $3 \div 4 \times 10^{13}$ & $2 \times 10^{14}$ & $4 \div 5 \times 10^{18}$ \\
\hline
\end{tabular}

*Rough estimations assuming the loops $\{111\}$ contain a single layer tellurium.

precipitate is $\mathrm{Ga}$-Te phase we could expect several tens times higher Te signal than observed. Moreover, $\mathrm{Ga} / \mathrm{As}$ ratios are similar in matrix and in precipitate. The close similarity of EDX spectrum from precipitate and matrix regions suggests that the precipitate contains not more than a few times higher concentration of Te than matrix. Thus an equivalent concentration of Te atoms involved in the precipitates could be estimated to about $10^{16} \mathrm{~cm}^{-3}$ from density of precipitates given in Table.

\section{Conclusions}

1. The rough coincidence between the change of free electron concentration and the creation of extended type defects is observed.

2. Estimated amount of Te atoms in extended defects seems to be too small to account for measured changes of free electron concentration caused by an annealing.

\section{Acknowledgments}

The work was partially supported by the Committee for Scientific Research within grant 3P 407-031-07. JEOL JEM 3010 electron microscope was granted by the Foundation for Polish Science within Sezam Program.

\section{References}

[1] P.W. Hutchinson, P.S. Dobson, Philos. Mag. 30, 65 (1974).

[2] S. Muto, S. Takeda, M. Hirata, K. Fujii, Philos. Mag. A 66, 257 (1992).

[3] M.S. Abrahams, J. Blanc, C.J. Buiocchi, J. Appl. Phys. 45, 3277 (1974).

[4] T. Kamejima, J. Matsui, Y. Seki, H. Watanabe, J. Appl. Phys. 50, 3312 (1979).

[5] C.S. Fuller, K.B. Wolfstirn, J. Appl. Phys. 34, 2287 (1963).

[6] B. Hughes, G.H. Narayanan, Phys. Status. Solidi A 46, 627 (1978).

[7] L.J. Van Der Pauw, Philips Res. Rep. 13, 1 (1958).

[8] R. Gevers, A. Art, S. Amelinckx, Phys. Status Solidi 3, 1563 (1963).

[9] P. Hirsh, A. Howie, R.B. Nicholson, D.W. Pashley, M.J. Whelan, Electron Microscopy of Thin Crystals, Butterworths, London 1965, Ch. 11. 